\title{
Tai Chi as a Potential Intervention for Symptoms of Mild Traumatic Brain Injury in Veterans
}

\author{
Hannah Roggenkamp ${ }^{1,3 *}$ and Ge Li ${ }^{1,2,3}$ \\ ${ }^{1}$ Veterans Affairs (VA) Northwest Network (VISN 20) Mental Illness, Research, Education, and Clinical Center (MIRECC), USA \\ ${ }^{2}$ VA Northwest Network (VISN 20) Geriatric Research, Education and Clinical Center (GRECC), USA \\ ${ }^{3}$ Department of Psychiatry and Behavioral Sciences, University of Washington School of Medicine, USA
}

Submission: December 16, 2017; Published: April 16, 2018

*Corresponding author: Hannah Roggenkamp, Department of Psychiatry and Behavioral Sciences, University of Washington School of Medicine, VA Puget Sound Health Care System, Mail Code S-116-MIRECC, 1660 South Columbian Way, Seattle, WA, 98108, USA, Tel: 1-206-277-5092; Email: hannah.roggenkamp2@va.gov

\begin{abstract}
Many Veterans of the conflicts in Afghanistan/Iraq who experienced repeated concussions due to blast exposure, also referred to as mild traumatic brain injury (mTBI), have persistent post-concussive symptoms (PCS). Additionally, these Veterans often have comorbid, overlapping posttraumatic stress disorder (PTSD) symptoms that further impact recovery. PCS include sleep disturbance, headaches, musculoskeletal pain, anxiety, dizziness/balance problems, fatigue, insomnia, impaired concentration and attention, memory problems, and increased irritability. Veterans with mTBI and PCS tend to have higher rates of unemployment and disability, report a decline in self-rated health and often suffer from anxiety and depressed mood. Multi-modal treatment options remain very limited. Emerging evidence supports the effectiveness of Tai Chi in improving physical and mental well-being, including many common PCS. Adverse events reported in Tai Chi studies tend to be on par with other exercise interventions. Despite this, potential health and physiological benefits of Tai Chi practice in Veterans with mTBI have not been investigated. Physiologically, TBI is associated with chronic autonomic dysregulation along with elevated levels pro-inflammatory cytokines causing neuroinflammation. Numerous studies have demonstrated decreases in pro-inflammatory immune markers following Tai Chi practice. In addition, Tai Chi studies of physiologic measures of noradrenergic function demonstrate short-term decreases in sympathetic tone, and overall greater parasympathetic outflow in Tai Chi practitioners. Given the vast potential for Tai Chi as a treatment modality for mTBI and associated comorbidities, controlled trials, especially in Veterans, are sorely needed.
\end{abstract}

Keywords: Mild traumatic brain injury; Tai chi; Post-concussive symptoms; Veterans; Blast-related

Abbreviations: mTBI: Mild Traumatic Brain Injury; PCS: Post-Concussive Symptoms; PTSD: Posttraumatic Stress Disorder; SM: Service Members; VA: Veterans Affairs

\section{Background}

\section{Chronic complex symptoms in combat-related mTBI}

Many Veterans who experienced repeated blast mild traumatic brain injury (mTBI) have persistent post-concussive symptoms (PCS), often with comorbid, overlapping PTSD symptoms that further impact recovery [1,2]. PCS include sleep disturbance, headaches, musculoskeletal pain, anxiety, dizziness/balance problems, fatigue, insomnia, impaired concentration and attention, memory problems, and increased irritability [1]. Veterans with mTBI and resultant persistent PCS tend to have higher rates of unemployment and disability [3] and report a decline in self-rated health $[4,5]$. Deploymentacquired mTBI is often comorbid with PTSD, and a recent study demonstrated that mTBI increases the likelihood of subsequent anxiety and depressed mood [6]. Current treatments are typically fragmented among multiple providers and benefit is often marginal. The efficacy of Tai Chi in individual cognitive and behavioral interventions for PCS and MTBI in civilians has been explored [7], but few therapies have been studied in Veterans. Most relevant studies tend to suffer from methodological issues and do not adequately address all symptom domains -a multidisciplinary treatment plan appears necessary but has not been standardized or adequately studied. Multi-modal and safe treatment approaches are sorely needed.

\section{Tai Chi: a mind-body intervention}

Tai Chi is a centuries-old martial art that originated in China and has become increasingly popular as a movement meditation in the West over the past 30 years. Multiple styles exist, but all share slow intentional movements coordinated with breathing and imagery. Tai Chi has been increasingly studied - a recent Veterans Affairs (VA) -driven meta-analysis identified 107 
distinct reviews of studies of Tai Chi as a clinical intervention [8]. Studies support the effectiveness of Tai Chi in improving physical and mental well-being in both healthy subjects $[9,10]$ and in subjects with medical morbidities. For example, a trial $(\mathrm{N}=88)$ comparing participants who engaged in a Tai Chi intervention to sedentary controls, found significant improvement in blood pressure readings as well decreases in both state and trait anxiety [11].

Multiple studies have demonstrated the efficacy of Tai Chi in improving individual PCS, as summarized in Table 1. Those studies include a trial of the effect of Tai Chi on headache severity, which showed improvement in patients randomized to a 15 week Tai Chi intervention vs waitlist control $(\mathrm{N}=30)$ [12]. Several studies have shown improvements in anxiety after Tai Chi training compared to a variety of control conditions, including treatment as usual
( $\mathrm{N}=139,2 / 3$ female participants), martial arts training $(\mathrm{N}=68$, mostly over age 60$)$, and medication management $(\mathrm{N}=80$, mean age 65 , and $\mathrm{N}=90$, young healthy participants) [13]. Insomnia has been examined in multiple studies, with beneficial results in healthy older adults over $60(\mathrm{~N}=112)$ [14], and Tai Chi was found to be as effective as empirically validated cognitive behavioral therapy for insomnia in 123 older adults [15]. Studies of changes in cognitive functioning have mostly been done in older adults, but demonstrate improvements in attention and executive functioning [16]. Tai Chi has been efficacious in treating complex multi-domain symptoms, which was recently demonstrated in clinical trials of Tai Chi in fibromyalgia patients, who showed improved functioning and improvements in sleep quality, pain, mood and quality of life. Clinical efficacy was demonstrated in anxiety treatment in a 5-week Tai Chi trial, indicating that even short trials of Tai Chi practice can have measurable effects [17].

Table 1: Randomized controlled trials of Tai Chi's effect on PCS and quality of life.

\begin{tabular}{|c|c|c|c|}
\hline PCS & Participants & Duration, Frequency & Outcome \\
\hline Headache [12] & $N=13$, both sexes & $15 w k s, 2 x / w k$ & $\begin{array}{l}\downarrow \text { headache impact on Headache } \\
\text { Impact Test- } 6\end{array}$ \\
\hline Anxiety $[13,17]$ & $\mathrm{N}=359$, patients with morbidities & $5-24 w k s, 2-4 x / w k$ & $\downarrow$ anxiety across morbidities \\
\hline Insomnia $[14,40,41]$ & $\mathrm{N}=408$; mostly elderly patients & $12-24 w k s, 1-5 x / w k$ & $\begin{array}{l}\text { 个sleep on Pittsburgh Sleep Quality } \\
\text { Index }\end{array}$ \\
\hline $\begin{array}{l}\text { Concentration/ } \\
\text { Attention deficits [16] }\end{array}$ & $\mathrm{N}=125$; elderly patients & 24wks-3 years, 3x/wk & $\begin{array}{c}\uparrow \text { attention focus time, } \downarrow \text { attention } \\
\text { dispersal }\end{array}$ \\
\hline Memory impairment [16] & $\mathrm{N}=213$; elderly patients & $24-40 w k s, 3-7 x / w k$ & $\uparrow$ memory measures \\
\hline $\begin{array}{l}\text { Irritability/ } \\
\text { Anger [20] }\end{array}$ & $\mathrm{N}=9$, mixed $\mathrm{TBI}$, civilians & $6 \mathrm{wks}, 2 \mathrm{x} / \mathrm{wk}$ & $\begin{array}{c}\downarrow \text { anger on Visual Analog Mood } \\
\text { Scale }\end{array}$ \\
\hline Dizziness [38] & $\mathrm{N}=20$, elderly men & $18 w k s, 2 x / w k$ & Improves dynamic balance \\
\hline Fatigue [39] & $\mathrm{N}=42$, women with breast cancer & $14 w k s, 1 x / w k$ & $\begin{array}{c}\downarrow \text { fatigue on Fatigue Symptom } \\
\text { Inventory }\end{array}$ \\
\hline Health-related quality of life [42] & N=989; multiple morbidities & $4-24 w k s$ & Improvement in overall HRQOL \\
\hline
\end{tabular}

PCS: Post-Concussive Symptoms; PSQI: Pittsburgh Sleep Quality Index; HRQOL: Health-Related Quality of Life; wk/wks: Week/Weeks

\section{Safety of Tai Chi}

Adverse Events (AEs) reported in Tai Chi studies tend to be on par with other exercise interventions and not as prevalent as in combat-oriented martial arts [18]. However, a review of randomized controlled trials (RCTs) of Tai Chi found that only a small fraction of published trials included AE reports at all, and those reports were frequently incomplete [18]. Most common $\mathrm{AE}$ reported were minor musculoskeletal aches and pains, particularly lower extremity pain, along with reports of back pain [18]. No serious AE have been reported in the literature [18].

\section{Mind-body interventions in veterans with mTBI}

Potential health benefits of Tai Chi practice specifically in Veterans with mTBI have not been investigated. Two small civilian studies of Tai Chi, for varying levels of TBI, yielded improvements in measures of mood and relaxation but did not assess PCS directly $[19,20]$. Two feasibility studies of Qigong practice, a mind-body intervention similar to Tai Chi, reported in 6 [21] and 16 [22] military Service Members (SM) with mTBI, found improved mood and sleep, and decreased stress, anxiety, and pain. They also demonstrated the feasibility of a mind-body intervention in SM, including minimal adverse effects and the suitability of such interventions in mTBI patients.

\section{Potential mechanisms of Tai Chi's effect on PCS}

TBI is associated with chronic autonomic dysregulation along with elevated levels of central and peripheral pro-inflammatory cytokines causing neuroinflammation [23-25]. Numerous studies have demonstrated a decrease in cytokines and proinflammatory immune markers $[15,26,27]$ and increased cellmediated immune response [28-30] following Tai Chi practice, but this has not been studied in mTBI or PTSD groups. In addition, multiple studies have demonstrated a decrease in inflammatory gene transcription after Tai Chi interventions [15,27]. Tai Chi studies of physiologic measures of noradrenergic function demonstrate short-term decreases in sympathetic tone via 
mechanisms which include vagal modulation [10,31,32], though it remains unclear how long new practitioners must engage in Tai Chi to have lasting noradrenergic modulation. Increased heart rate variability and overall greater parasympathetic outflow were demonstrated in long term Tai Chi practitioners compared to sedentary matched controls [33].

\section{Future Research Directions}

The evidence base for Tai Chi as an intervention for a variety of medical and psychiatric complaints is increasing exponentially, and has shown efficacy in reducing individual PCS. Recent feasibility studies in Veterans show that Tai Chi is a positively regarded intervention both in residential and outpatient settings [34-36]. Despite these encouraging results, many knowledge gaps persist. Tai Chi is an art which constantly evolves, and teaching methods can vary widely [37]. There is no standardized frequency of Tai Chi practice established in previously published Tai Chi studies, few long-term prospective studies exist, and sample sizes are often small. Generalizability is further limited in relevant studies due to a lack of an appropriate active control group, variable session durations ranging from 20 minutes to 2 hours, or an exclusive focus on elderly participants. Symptom improvement could largely be driven by placebo effects of the group experience; in addition, trials differ vastly in length, and it is not evident that longer treatment courses, i.e., 12 weeks, yield results superior to shorter trials of Tai Chi. While the increased availability of Tai Chi in medical centers such as the VA is a positive development, the lack of high quality placebo controlled trials and the uncertainty about needed treatment length leave clinicians without guidance regarding to whom and when to recommend Tai Chi. Future studies need larger numbers of participants and active control groups (such as a walking intervention), and would ideally compare outcomes of different treatment durations. More variety is needed in the populations studied, as healthy controls and younger patients are often excluded. Despite these ongoing challenges, Tai Chi remains a promising potential treatment option for Veterans with mTBI [38-42].

\section{Conclusion}

There is clear evidence that Tai Chi practice could improve multiple PCS, such as headache, dizziness, poor concentration, along with PTSD, anxiety and depression that are commonly seen in the Veterans with mTBI. However, there exists very limited data on whether Tai Chi is effective for treatment of PCS in mTBI and few existing Tai Chi studies have been conducted with Veterans. Given the symptom and physiological benefits, and demonstrated relative safety of Tai Chi, controlled trials in Veterans with mTBI are sorely needed.

\section{References}

1. Hoge CW, McGurk D, Thomas JL, Cox AL, Engel CC, et al. (2008) Mild traumatic brain injury in U.S. soldiers returning from Iraq. N Engl J Med 358(5): 453-463.
2. RAND (2008) Invisible wounds of war: psychological and cognitive injuries, their consequences, and services to assist recovery. Santa Monica, CA, RAND, USA.

3. Baldassarre M, Smith B, Harp J, Herrold A, High WM, et al. (2015) Exploring the relationship between mild traumatic brain injury exposure and the presence and severity of postconcussive symptoms among veterans deployed to Iraq and Afghanistan. PMR 7(8): 845-858.

4. Aralis HJ, Macera CA, Rauh MJ, Macgregor AJ (2014) Traumatic brain injury and PTSD screening efforts evaluated using latent class analysis. Rehabil Psychol 59(1): 68-78.

5. Janak JC, Cooper DB, Bowles AO, Alamgir AH, Cooper SP, et al. (2015) Completion of multidisciplinary treatment for persistent postconcussive symptoms is associated with reduced symptom burden. J Head Trauma Rehabil 32(1): 1-15.

6. Stein MB, Kessler RC, Heeringa SG, Jain S, Campbell Sills L, et al. (2015) Prospective longitudinal evaluation of the effect of deploymentacquired traumatic brain injury on posttraumatic stress and related disorders: results from the army study to Assess risk and resilience in servicemembers (Army STARRS). Am J Psychiatry 172(11): 11011111.

7. Cooper DB, Bunner AE, Kennedy JE4, Balldin V, Tate DF, et al. (2015) Treatment of persistent post-concussive symptoms after mild traumatic brain injury: a systematic review of cognitive rehabilitation and behavioral health interventions in military service members and veterans. Brain Imaging Behav 9(3): 403-420.

8. Solloway MR, Taylor SL, Shekelle PG, Miake Lye IM, Beroes JM, et al. (2016) An evidence map of the effect of Tai Chi on health outcomes. Syst Rev 5(1): 126.

9. Lu WA, Kuo CD (2014) Breathing frequency-independent effect of Tai Chi Chuan on autonomic modulation. Clin Auton Res 24(2): 47-52.

10. Nedeljkovic M, Ausfeld Hafter B, Streitberger K, Seiler R, Wirtz PH (2012) Taiji practice attenuates psychobiological stress reactivity - A randomized controlled trial in healthy subjects. Psychoneuroendocrinology 37(8): 1171-1180.

11. Tsai JC, Wang WH, Chan P, Lin LJ, Wang CH, et al. (2003) The beneficial effects of Tai Chi Chuan on blood pressure and lipid profile and anxiety status in a randomized controlled trial. J Altern Complement Med 9(5): 747-754.

12. Abbott RB1, Hui KK, Hays RD, Li MD, Pan T (2007) A Randomized controlled trial of Tai Chi for tension headaches. Evid Based Complement Alternat Med 4(1): 107-113.

13. Wang F, Lee EK, Wu T, Benson H, Fricchione G, et al. (2014) The Effects of Tai Chi on depression, anxiety, and psychological well-being: a systematic review and meta-analysis. Int J Behav Med 21(4): 605-617.

14. Irwin MR, Olmstead R, Motivala SJ (2008) Improving sleep quality in older adults with moderate sleep complaints: A randomized controlled trial of Tai Chi Chih. Sleep 31(7): 1001-1008.

15. Irwin MR, Olmstead R, Breen EC, Witarama T, Carrillo C, et al. (2015) Cognitive behavioral therapy and Tai Chi reverse cellular and genomic markers of inflammation in late-life insomnia: a randomized controlled trial. Biol Psychiatr 78(10): 721-729.

16.Zheng G, Liu F, Li S, Huang M, Tao J, et al. (2015) Tai Chi and the protection of cognitive ability: a systematic review of prospective studies in healthy adults. Am J Prev Med 49(1): 89-97.

17. Wang C, Bannuru R, Ramel J, Kupelnick B, Scott T, et al. (2010) Tai Chi on psychological well-being: systematic review and meta-analysis. BMC Complementary and Alternative Medicine 10: 23.

18. Wayne PM, Berkowitz DL, Litrownik DE, Buring JE, Yeh GY (2014) What do we really know about the safety of Tai Chi?: A systematic 
review of adverse event reports in randomized trials. Arch Phys Med Rehabil 95(12): 2470-2483.

19. Blake H, Batson M (2009) Exercise intervention in brain injury: a pilot randomized study of Tai Chi Qigong. Clin Rehabil 23(7): 589-598.

20. Gemmell C, Leathem JM (2006) A study investigating the effects of Tai Chi Chuan: Individuals with traumatic brain injury compared to controls. Brain Inj 20(2): 151-156.

21. Reb AM, Saum NS, Murphy DA, Breckenridge Sproat ST, Su X, et al. (2016) Qigong in injured military service members: a feasibility study. J Holist Nurs 35(1): 10-24.

22. Yost TL, Taylor AG (2013) Qigong as a novel intervention for service members with mild traumatic brain injury. Explore (NY) 9(3): 142149.

23. Di Battista AP, Rhind SG, Hutchison MG, Hassan S, Shiu MY, et al. (2016) Inflammatory cytokine and chemokine profiles are associated with patient outcome and the hyperadrenergic state following acute brain injury. J Neuroinflammation 13: 40.

24. Hilz MJ, Liu M, Koehn J, Wang R, Ammon F, et al. (2016) Valsalva maneuver unveils central baroreflex dysfunction with altered blood pressure control in persons with a history of mild traumatic brain injury. BMC Neurol 16: 61.

25. Meabon JS, Huber BR, Cross DJ, Richards TL, Minoshima S, et al (2016) Repetitive blast exposure in mice and combat veterans causes persistent cerebellar dysfunction. Sci Transl Med 8(321): 321ra326321 ra326.

26. Campo RA, Light KC, O’Connor K, Nakamura Y, Lipschitz D, et al. (2015) Blood pressure, salivary cortisol, and inflammatory cytokine outcomes in senior female cancer survivors enrolled in a Tai Chi Chih randomized controlled trial. J Cancer Surviv 9(1): 115-125.

27. Irwin MR, Olmstead R, Breen EC, Witarama T, Carrillo C, et al. (2014) Tai Chi, cellular inflammation, and transcriptome dynamics in breast cancer survivors with insomnia: a randomized controlled trial. J Natl Cancer Inst Monogr 2014(50): 295-301.

28. Irwin MR, Olmstead R, Oxman MN (2007) Augmenting Immune Responses to Varicella Zoster Virus in Older Adults: A Randomized, Controlled Trial of Tai Chi. J Am Geriatr Soc 55(4): 511-517.

29. Yang KD, Chang WC, Chuang H, Wang PW, Liu RT, et al. (2010) Increased complement factor $\mathrm{H}$ with decreased factor $\mathrm{B}$ determined by proteomic differential displays as a biomarker of Tai Chi chuan exercise. Clin Chem 56(1): 127-131.

30. Yeh SH, Chuang H, Lin LW, Hsiao CY, Wang PW, et al. (2009) Regular Tai Chi Chuan exercise improves $\mathrm{T}$ cell helper function of patients with type 2 diabetes mellitus with an increase in T-bet transcription factor and IL-12 production. Br J Sports Med 43(11): 845-850.

31. Cole AR, Wijarnpreecha K, Chattipakorn SC, Chattipakorn N (2016) Effects of Tai Chi exercise on heart rate variability. Complement Ther Clin Pract 23: 59-63.

32. Figueroa MA, Demeersman RE, Manning J (2012) The autonomic and rate pressure product responses of Tai Chi practitioners. N Am J Med Sci 4(6): 270-275.

33. Lu WA, Kuo CD (2003) The Effect of Tai Chi chuan on the autonomic nervous modulation in older persons. Med Sci Sports Exerc 35(12): 1972-1976

34. Gaddy M (2017) Implementation of an integrative medicine treatment program at a veterans health administration residential mental health facility. Psychol Serv.

35. Niles BL, Mori DL, Polizzi CP, Pless Kaiser A, Ledoux AM, et al. (2016) Feasibility, qualitative findings and satisfaction of a brief Tai Chi mindbody programme for veterans with post-traumatic stress symptoms. BMJ Open 6(11).

36. Tsai PF, Kitch S, Chang JY, James GA, Dubbert P, et al. (2017) Tai Chi for posttraumatic stress disorder and chronic musculoskeletal pain: a pilot study. J Holist Nurs 1: 898010117697617.

37. Wayne PM, Kaptchuk TJ (2008) Challenges inherent to T'ai Chi research: part ii-defining the intervention and optimal study design. J Altern Complement Med 14(2): 191-197.

38. Maciaszek J, Osinski W (2012) Effect of Tai Chi on body balance: randomized controlled trial in elderly men with dizziness. Am J Chin Med 40(2): 245-253.

39. Larkey LK, Roe DJ, Weihs KL, Jahnke R, Lopez AM, et al. (2015) Randomized controlled trial of Qigong/Tai Chi easy on cancer-related fatigue in breast cancer survivors. Ann Behav Med 49(2): 165-176.

40. Sarris J, Byrne GJ (2011) A systematic review of insomnia and complementary medicine. Sleep Med Rev 15(2): 99-106.

41. Wang F, Eun Kyoung Lee O, Feng F, Vitiello MV, Wang W, et al. (2016) The effect of meditative movement on sleep quality: A systematic review. Sleep Medicine Reviews 30: 43-52.

42.Zhang F, Kong LL, Zhang YY, Li SC (2012) Evaluation of Impact on health-related quality of life and cost effectiveness of traditional chinese medicine: a systematic review of randomized clinical trials. J Altern Complement Med 18(12): 1108-1120.

\section{Your next submission with Juniper Publishers} will reach you the below assets

- Quality Editorial service

- Swift Peer Review

- Reprints availability

- E-prints Service

- Manuscript Podcast for convenient understanding

- Global attainment for your research

- Manuscript accessibility in different formats

( Pdf, E-pub, Full Text, Audio)

- Unceasing customer service

Track the below URL for one-step submission https://juniperpublishers.com/online-submission.php 